\title{
Current Status of Farmers' Climate Change Adaptation: The Case of Ethiopia
}

\author{
Shegaw Yesgat Hailu* \\ Lecture and head, Department of Geography and Environmental studies, Wollo University, Dessie, Ethiopia \\ *Corresponding Author: Shegaw Yesgat Hailu, Lecture and head, Department of Geography and \\ Environmental studies, Wollo University, Dessie, Ethiopia
}

\begin{abstract}
Agriculture is the backbone of Ethiopia's economy, but the sector is affected by negative impact of climate change and variability such as: recurrent drought and floods. This is because of low adaptive capacity of farmers, high vulnerability of the sector and lack of addressing the available adaptation opportunities, constraints and limits. Successful adaptation needs exploiting available adapation options and reducing barier adapation options expanding the adaptive capacity of farmers and natural systems. The paper focuses on two issues of overlap that include: (1) agriculture and climate change adaptations (2) types and determinants of adaptations options focusing on rural Ethiopia.
\end{abstract}

Keywords: Climate change Adaptation, Agriculture, Adaptation options

\section{INTRODUCTION}

As impacts of climate change have become apparent around the world, adaptation has attracted increasingly the attention of researchers, development agents and policy makers. The impacts are particularly severe in the developing world and among marginalized communities because of limited adaptive capacity (Mimura et al., 2014).

Throughout history, people and societies have adjusted to and coped with climate, climate variability, and extremes, with varying degrees of success ((Field, Barros, Mach, \& Mastrandrea, 2014). The combined efforts of a broad range of international organizations, scientific reports, and media coverage have raised awareness of the importance of adaptation to climate change, fostering a growing number of adaptation responses in developed and developing countries(Mimura et al., 2014).

Adaptation process through which societies make themselves betterto cope with an uncertain future. Adapting to climate change entails taking the right measures to reduce the negative effects of climate change (or exploit the positive ones) by making the appropriate adjustments and changes.(McGray, Hammill, Bradley, Schipper, \& Parry, 2007). Adaptation practices refer to actual adjustments, or changes in decision environments, which might ultimately enhance resilience or reduce vulnerability to observed or expected changes in climate(Adger et al., 2007).

Adaptation to climate change has now become part of the contemporary discourse about the politics and economics of global climate change. It has been enshrined in the policy debate through its appearance in Article 2 of the United Nations Framework Convention on Climate Change (UNFCCC), where the ultimate objective of the Convention concedes that adaptation to climate change in relation to food production, ecosystem health and economic development can and will occur (Adger et al., 2007).Climate change adaptation has been receiving increasing attention as a result of recent media coverage and reports. Since the publication of the IPCC Fourth Assessment Report (AR4), a large assortment of adaptive actions has taken place in response to observed climate impacts. . Globally, more than $70 \%$ of agriculture is rain fed (Porter et al., 2014). This suggests that agriculture, food security, and nutrition are all highly sensitive to climate change. Adaptation outcomes focusing on ensuring food security under a changing climate could have the most direct benefits on livelihoods, which have multiple benefits for food security, including enhancing food production, access to markets and resources, and reduced disaster risk (Porter et al., 2014).

As it was stated by alliance for in Africa (AGRA 2014) the good news is that there are interventions applicable to African farming systems that will simultaneously increase yields, increase resilience to 
climate change, reduce GHG emissions, and increase the stock of carbon in the soil. Climate-smart agriculture (CSA) is an approach for addressing food security challenges under the new realities of climate change. Since 2007, Africa has gained experience in conceptualizing, planning, and beginning to implement and support adaptation activities, from local to national levels and across a growing range of sectors ( Niang et al.,2014)..In sub Saharan Africa, small holder farmers are the primary producers of agricultural outputs. They account for about $80 \%$ of all the farms in sub-Saharan Africa. They directly employ about 175 million, and about $70 \%$ of all smallholders are women (AGRA 2014). Sub-Saharan Africa is confronted with a range of climate risks that could have far-reaching consequences to its agricultural systems in the future (AGRA 2014). Despite implementation limitations, Africa's adaptation experiences nonetheless highlight valuable lessons for enhancing and scaling up the adaptation response, including principles for good practice and integrated approaches to adaptation (Niang et al., 2014).

Developing countries are likely to be affected by climate change, and Ethiopia is one of the most vulnerable countries. Unless adaptation measures are widely implemented, climate change can set back development efforts and achievements by years (Adem \& Bewket, 2011). Ethiopia ratified the UNFCCC (1994) and its related instrument, the Kyoto Protocol (2005), and submitted its initial national communications (in 2001) and National Adaptation Program of Action (NAPA) (in 2007) to the UNFCCC. The country has also submitted its Nationally Appropriate Mitigation Action (NAMA) plan to the UNFCCC by the end of January 2010. The country has completed the preparation of a new work program for action. Ethiopian Program of Adaptation to Climate Change (EPACC), which replaces the project-based NAPA, and is in the process of developing an overarching framework and national strategy called Climate Resilient Green Economy(CRGE) (Adem \& Bewket, 2011).

\section{Agriculture AND CLIMATE CHANGE ADAPTATION}

Adaptation to climate change is already taking place, but on a limited basis (Adger et al., 2007). According to (Klein et al2015) there is evidence of opportunities in natural and human systems to adapt to climate changes. There is also evidence that the potential to adapt is constrained, or more difficult in some situations, and faces limitation.

Adaptive capacity is influenced by actors' abilities to capitalize on available opportunities that ease the planning and implementation of adaptation as well as constraints that make adaptation processes more difficult for both human and natural systems.

According to Dasgupta etal.,(2014), the largest known economic impact of climate change is on agriculture because of the size and sensitivity of the sector, particularly in the developing world and to a lesser extent in parts of the developed world.

Agriculture is the foundation of Ethiopia's economy, accounting for $41 \%$ of gross domestic Product (GDP), about $90 \%$ of exports and $81 \%$ of total employment (Mahoo, Radeny, Kinyangi, \& Cramer, 2013).Many scholars also stated that Ethiopian agriculture is most vulnerable to drought[(Doty et al., 2011), (AGRA 2014), (Bryan, Deressa, Gbetibouo, \& Ringler, 2009), (T. T. Deressa, Hassan, Ringler, Alemu, \& Yesuf, 2009), (Adem \& Bewket, 2011)(Economy, 2011)]. Again many literature stated that Ethiopia is highly affected by climate change [ (AGRA, 2014, cited in (FAO, 2010), (Adem \& Bewket, 2011),(Simane, Zaitchik, \& Mesfin, 2012), (Yirgu, Nicol, \& Srinivasan, 2013) ].

Climate related hazards in Ethiopia includes drought, floods, heavy rains, strong winds, frost, heat waves (high temperatures)(Economy, 2011).Crop production in Ethiopia is affected by failure of rains or occurrence of successive dry spells during the growing season. Food shortages resulting from adverse weather conditions are not new in Ethiopia (Mahoo et al., 2013).

Climate related hazard that affects Ethiopia from time to time is flood and drought.

Major floods which caused loss of life and property occurred in different parts of the country in 1988, 1993, 1994, 1995, 1996 and 2006 and major drought history which caused loss of life and property occurred in Wollo in 1953, 1957-58,1964-1966 1.5 million people were affected and in 1973-1974 a total of 200,000 people and 30\% of livestock were dead (Economy, 2011).

Another researcher (Doty et al., 2011)stated that, widespread drought and extreme rainfall variation in the Wollo Afar, Tigray, and northern Amhara disrupted precarious ecosystems and food supplies vital to the Ethiopian livelihood. 
South Wollo, has long history of different climate change related risks, In the year 2014-15, a total of from 30258 hectare land 244503 quintal major crops Teff, Maize and Wheat was damaged during the period of pre harvesting and post harvesting time (SWAO 2014-2015). This damaged mainly caused by small rain / drought, flood, crop diseases, pests and land slide climate change/variability related risks.

According to (Seid, 2013) a study conducted in south Wollo, rural peoplehave started to adopt climate change and variability such us: planting trees, soil conservations cultivating different crops etc. Even if, farmers used such kind of adaptations practices, they faced different adaptation problems including knowledge about application and usage of new technology, cultural and institutional problems. In addition to this, there are physical and biological barriers and limitations to adapt the current climate change risks. Of course there are many adaptation climate change adaptation policy at country level it can be considered as opportunities, for instance: National Adaptation Program of Action (NAPA) and Climate Resilient Green Economy (CRGE). Farmers are getting different climate information from the local government offices but it's not satisfactory.

Adaptations options were did not implemented properly. Some adaptive actions may turn out maladaptive later.(Moser \& Ekstrom, 2010).This is due to lack of addressing the available adaptation opportunities, constraints and limits. Successful adaptation requires not only identifying adaptation options and assessing their costs and benefits, but also exploiting available mechanisms for expanding the adaptive capacity of human and natural systems (Klein et al., 2015).Thus, seizing opportunities, overcoming constraints, and avoiding limits can involve complex governance challenges and may necessitate new institutions and institutional arrangements to effectively address (Klein et al., 2015) to climate change related risks on agriculture.

\section{TYPES AND DETERMINANTS OF ADAPTATION OPTIONS}

In order to adapt to climate change, farmers must first perceive that changes are taking place (Bryan et al., 2009). Most Ethiopian farmers perceived that, temperature has been increasing overtime and rainfall decreased [(Bryan et al., 2009); (Tessema, Aweke, \& Endris, 2013)]. Farmers living in Dega (highlands) perceived more change in climate than farmers in Kola (lowland) or Woinadega (midland) [(T. Deressa, Hassan, Alemu, Yesuf, \& Ringler, 2008)].

Another researcher [(T. T. Deressa et al., 2009)] investigated determinants of farmers' choice of adaptation methods to climate change in the Nile basin of Ethiopia, Results from the discrete choice model indicated that the level of education, gender, age, and wealth of the head of household; access to extension and credit; information on climate, social capital, agro ecological settings, and temperature all influence farmers' choices of adaptations. Comparative study from South Africa and Ethiopia (Bryan et al., 2009) on adaptations to climate change of options and constraints, the finding of this research shows that, Ethiopian farmer's adaptation options includes: use of different crops, planting trees, soil conservations changing planting dates and irrigations. And the main barriers to adaptation cited by farmers were lack of access to land, information, and credit. According to (Tessema et al., 2013) research based on understanding the process of adaptation to climate change by small-holder farmers: the case of east Hararghe zone, they find out that, the type of adaptations that farmers used mostly were tree planting and the main barrier of adaption in that study area was lack of information, like wise [(T. Deressa et al., 2008)].

\section{ACKNOWLEDGEMENT}

The outer thanks all staff of geography department who gave me valuable comments and suggestion.

\section{REFERENCES}

[1] Adem, A., \& Bewket, W. (2011). A climate change country assessment report for Ethiopia. Addis Ababa, Ethiopia: Epsilon International R\&D.

[2] Adger, W. N., Agrawala, S., Mirza, M. M. Q., Conde, C., O’Brien, K., Pulhin, J., Takahashi, K. (2007). Assessment of adaptation practices, options, constraints and capacity. Climate change, 717-743.

[3] Bryan, E., Deressa, T. T., Gbetibouo, G. A., \& Ringler, C. (2009). Adaptation to climate change in Ethiopia and South Africa: options and constraints. environmental science \& policy, 12(4), 413-426.

[4] Deressa, T., Hassan, R., Alemu, T., Yesuf, M., \& Ringler, C. (2008). Analyzing the determinants of farmers' choice of adaptation methods and perceptions of climate change in the Nile Basin of Ethiopia: Intl Food Policy Res Inst. 
[5] Deressa, T. T., Hassan, R. M., Ringler, C., Alemu, T., \& Yesuf, M. (2009). Determinants of farmers' choice of adaptation methods to climate change in the Nile Basin of Ethiopia. Global environmental change, 19(2), 248-255.

[6] Economy, C. R. G. (2011). Ethiopia's Climate Resilient Green Economy: Green Economy Strategy. Addis Ababa: FDRE.

[7] Field, C., Barros, V., Mach, K., \& Mastrandrea, M. (2014). Climate Change 2014: Impacts, Adaptation, and Vulnerability. Contribution of Working Group II to the fifth Assessment Report of the Intergovernmental Panel on Climate Change. Press Syndicate of the University of Cambridge, Cambridge, UK.

[8] Klein, R. J., Midgley, G. F., Preston, B. L., Alam, M., Berkhout, F. G., Dow, K., Butzer, K. W. (2015). Adaptation opportunities, constraints, and limits.

[9] Mahoo, H., Radeny, M., Kinyangi, J., \& Cramer, L. (2013). Climate change vulnerability and risk assessment of agriculture and food security in Ethiopia: which way forward?

[10] McGray, H., Hammill, A., Bradley, R., Schipper, E. L., \& Parry, J.-E. (2007). Weathering the storm: Options for framing adaptation and development. World Resources Institute, Washington, DC, 57.

[11] Mimura, N., Pulwarty, R., Duc, D., Elshinnawy, I., Redsteer, M., Huang, H., Rodriguez, R. S. (2014). Adaptation planning and implementation. Climate change, 869-898.

[12] Moser, S. C., \& Ekstrom, J. A. (2010). A framework to diagnose barriers to climate change adaptation. Proceedings of the National Academy of Sciences, 107(51), 22026-22031.

[13] Porter, J. R., Xie, L., Challinor, A. J., Cochrane, K., Howden, S. M., Iqbal, M. M., . . Garrett, K. (2014). Food security and food production systems.

[14] Seid, M. (2013). Community Perception and Indigenous Adaptive Response to Climate Variability at Tehuledere Woreda, South Wollo. Engineering International, 1(2), 18-26.

[15] Simane, B., Zaitchik, B. F., \& Mesfin, D. (2012). Building climate resilience in the Blue Nile/Abay Highlands: A framework for action. International journal of environmental research and public health, 9(2), 610-631.

[16] Tessema, Y. A., Aweke, C. S., \& Endris, G. S. (2013). Understanding the process of adaptation to climate change by small-holder farmers: the case of east Hararghe Zone, Ethiopia. Agricultural and Food Economics, 1(1), 13.

[17] Yirgu, L., Nicol, A., \& Srinivasan, S. (2013). Warming to Change? Climate Policy and Agricultural Development in Ethiopia.

Citation: Shegaw Yesgat Hailu. "Current Status of Farmers' Climate Change Adaptation: The Case of Ethiopia ". International Journal of Research in Geography, vol. 5, no.4, 2019, pp. 19-22. doi: http://dx.doi. org/10.20431/2454-8685.0504002.

Copyright: (C) 2019 Authors. This is an open-access article distributed under the terms of the Creative Commons Attribution License, which permits unrestricted use, distribution, and reproduction in any medium, provided the original author and source are credited. 